Letters to the Editor

\section{Localized lymphadenitis due to leishmania. Diagnosis by fine needle aspiration cytology}

Sir,

Localized leishmania lymphadenitis (LLL) is not a well known form of infection by Leishmania and is now considered as a limited form of visceral leishmaniasis (kala-azar) where lymphadenopathy is the only manifestation of the disease. ' In immunocompromised states, it can present as a focus of visceral dissemination of the parasite with an atypical clinical course. ${ }^{2}$ Although LLL is an uncommon cause of lymphadenopathy it should be considered in the differential diagnosis of patients presenting with enlargement of a single lymph node, especially where leishmaniasis is endemic, such as European countries bordering the Mediterranean, or in travellers from these areas. The diagnosis of leishmaniasis is made by visualizing leishmania organisms (Leishman-Donovani bodies) under the microscope. Culture of the parasite in Nicolle-Novy-McNeal's medium or others, skin and serological tests are not totally satisfactory.

We present two cases of LLL, both diagnosed by fine needle aspiration cytology (FNAC) from solitary lymphadenopathy. One case has been previously communicated. ${ }^{3}$

The first patient was a 28 year old female. She had been splenectomized because of significant haemolytic anaemia from a heterozygotic state of haemoglobin Lepore and beta-thalassaemia. She came back to the hospital for a periodical revision. On physical examination a preauricular lymph node was detected. Material from FNAC contained Leishmania organisms. After diagnosis, serology was positive. Then, we reviewed the slides from the spleen but no parasites were found. No treatment was given. The enlarged lymph node spontaneously regressed.

The other patient was a 43 year old male in complete remission from Hodgkin's disease. Similarly, in revision, an enlargement of an inguinal lymph node was found. The FNAC was diagnostic. Serology was negative. Treatment with meglumine antimonate (Glucantime) was initiated; the lymphadenopathy remitted and the patient was well 6 months after diagnosis.

FNAC is a diagnostic tool little known to the vast number of practicing clinicians. It is an atraumatic procedure that is acceptable to the patients. It is quick, cheap and reliable. ${ }^{4}$ It is generally used to verify, or rule out, malignancy of a target tumour, but identification of micro-organisms, by direct examination or by culture of the material aspirated, is another indication.

Diagnosis of Leishmania by recognition of the parasite in the cellular material obtained by FNAC has been reported from some cases of $\mathrm{LLL}^{3.5}$ and from one case of the cutaneous form. ${ }^{6}$ It is important therefore to remember this clinical entity, probably under-recognized, particularly in endemic regions and we wish to emphasize the utility of FNAC as a diagnostic method.

Ricardo Garcia-González
Itziar Sanz
Carlos Saus
José L. Calleja
Hospital 'Ramón y Cajal',
Madrid, Spain

\section{References}

1. Daneshbod, K. Localized lymphadenitis due to leishmania simulating toxoplasmosis. Value of electron microscopy for differentiation. Am J Clin Pathol 1978, 69: 462-467.

2. Fernandez-Guerrero, M.L. et al. Visceral leishmaniasis in immunocompromised hosts. Am J Med 1987, 83: 1098-1102.

3. Sanz, I., Hernandez, I., Varona, C., Melendez, F., Garcia, R. \& Navarro, P. Leishmania detection by lymph node FNAC. A case report. Abstract of the XIV European Congress of Cytology. Citologia (supplement) 1985, 7: 94-95.

4. Linsk, J.A. \& Franzen, S. Fine Needle Aspiration for the Clinician. J.B. Lippincott Co, Philadelphia, 1986, p. 2.

5. Kumar, P.V., Hambarsoomina, B. \& Vaezzadeh, K. Fine needle aspiration cytology of localized leishmania lymphadenitis. Acta Cytol 1987, 31: 14-16.

6. Perez-Guillermo, M., Hernandez-Gil, A. \& Bonnarti, C. Diagnosis of cutaneous leishmaniasis by fine needle aspiration cytology. Report of a case. Acta Cytol 1988, 32: 485-488.

\section{Hypoglycaemia in Sudanese children with cerebral malaria}

Sir,

Hypoglycaemia is an important complication of Plasmodium falciparum infection. Its aetiology appears to vary in different parts of the world; it is associated with hyperinsulinaemia due to the insulinotropic effect of quinine in Thai patients, ${ }^{1,2}$ with normal insulin levels in Gambian patients ${ }^{3}$ and with high alanine and lactate levels in both groups. ${ }^{1,2}$

In this preliminary study, we report on the occurrence of hypoglycaemia in 19 patients with cerebral malaria from Gedaref in Eastern Sudan. All patients were children (ages 4-11 years) with clinical symptoms of malaria, including neurological manifestations; subsequent investigations confirmed the presence of falciparum infection with moderate to severe parasitaemia. Whenever indicated a lumbar puncture was performed in order to exclude meningitis. Glucose, insulin and cortisol were assayed on plasma samples obtained from the patients on 
Table I Plasma glucose, insulin and cortisol levels in Sudanese children with cerebral malaria

\begin{tabular}{lcccc}
\hline & $\begin{array}{c}\text { Glucose } \\
\text { (mmolll) })\end{array}$ & $\begin{array}{c}\text { Insulin* } \\
(\mathrm{mU} / \mathrm{l})\end{array}$ & $\begin{array}{c}\text { Cortisol } \\
(\text { nmol } / \mathrm{l})\end{array}$ & Outcome \\
\hline $\begin{array}{l}\text { Normoglycaemic } \\
\text { patients }(n=15)\end{array}$ & $3.45 \pm 1.4$ & $7.5 \pm 7.2$ & $684 \pm 308$ & 2 died \\
$\begin{array}{l}\text { Hypoglycaemic } \\
\text { patients }(n=4)\end{array}$ & & & & \\
M.A. & 0.76 & 12.9 & $>1600$ & died \\
A.H. & 0.56 & 4.9 & 851 & died \\
H.A. & 0.56 & $<1.8$ & not done & died \\
M.J. & 1.70 & 5.7 & 546 & recovered \\
\hline
\end{tabular}

*Normal fasting level $3-15 \mathrm{mU} / \mathrm{l}$; tnormal $09.00 \mathrm{~h}$ level $440 \mathrm{nmol} / \mathrm{l}$.

admission before treatment, which consisted of intravenous quinine. None of the patients had had quinine prior to admission. Of the 19 patients, 4 had hypoglycaemia (blood glucose $<2.2 \mathrm{mmol} / \mathrm{l}$ ) of whom 3 died soon after admission. Alternatively, of the 15 normoglycaemic patients only 2 died (Table I). Except for patient H.A. who had an insulin level below the detection limit of the assay $(1.8 \mathrm{mU} / \mathrm{l})$, the other 3 hypoglycaemic patients had normal fasting insulin concentrations similar to those reported in Gambian children with severe malaria and hypoglycaemia ${ }^{3}$ and much lower than those reported in Thai childen who had received quinine before they were investigated.'

Ruling out hyperinsulinaemia as the cause of hypoglycaemia in our patients, the other possibilities may be increased demand for glucose by the parasite or by the patient (due to infection and fever), or inhibition of hepatic gluconeogenesis.' Since gluconeogenesis is enhanced by a low plasma insulin/glucagon ratio and a high plasma cortisol concentration, it appears from the present data that the hormonal status of our patients favours a normal operation of gluconeogenesis.

Our findings confirm that hypoglycaemia is a serious complication of cerebral malaria with an alarmingly high mortality. In our patients hypoglycaemia appears to be caused by the falciparum infection itself. However, with chloroquine resistance spreading in $\mathrm{Sudan}^{4}$ and phys- icians resorting back to quinine treatment, we are bound to see more of this complication in this country.

$$
\begin{array}{r}
\text { G.S. Atabani } \\
\text { B.O. Saeed } \\
\text { B.A. ElSeed } \\
\text { M.A. Bayoumi } \\
\text { N.H. Abdl Hadi } \\
\text { Y.A. Abu-Zeid } \\
\text { R.A. Bayoumi } \\
\text { Faculty of Medicine, University of Khartoum, } \\
\text { P.O. Box 102, Khartoum, and } \\
\text { Gedaref Hospital, Gedaref, Sudan. }
\end{array}
$$

\section{References}

1. White, N.J., Warrell, D.A., Chanthavanich, P. et al. Severe hypoglycemia and hyperinsulinemia in falciparum malaria. $N$ Engl J Med 1983, 309: 61-66.

2. Phillips, R.E., Looareesuwara, S., White, N.J. et al. Hypoglycaemia and anti-malarial drugs: quinidine and release of insulin. $\mathrm{Br}$ Med J 1986, 292: 1319-1321.

3. White, N.J., Miller, K.D., Marsh, K. et al. Hypoglycaemia in African children with severe malaria. Lancet 1987, i: 708-711.

4. Bayoumi, R.A., Babiker, H.A., Ibrahim, S.M. et al. Chloroquine resistant Plasmodium falciparum in Eastern Sudan. Acta Tropica 1989, 46: 157. 